\title{
MUSEU, COMUNICAÇÃO E PODER
} Renata Andreoni

\section{RESUMO}

A partir das reflexões de Manuel Castells sobre a Sociedade em Rede, Comunicação e Poder, o presente artigo analisa a inserção do museu contemporâneo neste processo. Desta forma, o texto busca elucidar a (re)significação, ocorrida nas últimas décadas, nesses espaços de memória/esquecimento. Após identificar o museu como um veículo de comunicação e núcleos de poder, foram realizadas considerações aos processos memorialistas que começam a demarcar espaços em empresas públicas e privadas.

Palavras-chave: sociedade em rede; museu, memória, poder.

\section{MUSEUM COMMUNICATION AND POWER}

\begin{abstract}
From the reflections produced by Manuel Castells about Society in Network, Communication and Power, the present article analyses the insertion of contemporary museums in this process. Therefore, the text aims to elucidate the (re)signification occurred in the last decades of these spaces of memory/forgetfulness. After identifying the museum as a vehicle of communication and nucleus of power, considerations were made concerning the memorialist processes that start demarcating spaces in public and private companies.
\end{abstract}

Keywords: society in network; museum; emory; power. 


\section{Introdução}

Este trabalho parte das reflexões apresentadas no livro Comunicación y Poder, de Manuel Castells. Publicado em 2009, o autor realizou uma exaustiva e profunda pesquisa, analisando a constituição e o exercício das relações de poder contemporâneas num contexto tecnológico das redes digitais e da comunicação globalizada. Nesse sentido, Castells busca compreender qual o papel das redes de comunicação na construção do poder, conduzindo sua tese com ênfase no poder político. A análise apresentada, nessa extensa obra, é proposta sobre uma estrutura social específica: a sociedade em rede, conceito consolidado pelo autor, sociólogo espanhol, em sua trilogia "A era da informação". A partir desses três volumes é possível identificar as transformações do cenário e da vida social, advindos dos acontecimentos que marcaram as últimas décadas do segundo milênio. As grandes transformações tecnológicas, principalmente as que se referem à tecnologia da informação, passaram a remodelar as estruturas e a dinâmica das sociedades na segunda metade do século XX.

A sociedade em rede conecta o mundo numa escala global, e nos conduz a ultrapassar barreiras continentais. Todavia interligadas, não são homogêneas no compartilhamento de valores e interesses. Pelo contrário, a contradição é característica fulcral das estruturas sociais, que são compostas por diferentes representações ${ }^{1}$ e identidades conflitantes. Nesse sentido, o multiculturalismo e a pluralidade que constituem a sociedade em rede demonstram que os conflitos e as negociações são processos constantes entre os atores sociais. "Estas relaciones implican acuerdos complejos entre diferentes niveles de práctica e instituciones: global, nacional, local e individual" (SASSEN, 2006 apud CASTELLS, 2009, p. 39). A sociedade se define em torno de valores e instituições, assim, o que é valorizado e institucionalizado é definido por relações de poder. Para Castells, o processo de construção de poder se dá por meio da capacidade relacional entre duas perspectivas: dominação e resistência, ambas baseadas na informação a partir de características diferentes/opostas, mas com a mesma

\footnotetext{
${ }^{1}$ Segundo Roger Chartier há três modalidades de articular a relação com o mundo social. “(...) de início, o trabalho de classificação e de recorte que produz configurações intelectuais múltiplas pelas quais a realidade é contraditoriamente construída pelos diferentes grupos que compõem uma sociedade, em seguida, as práticas que visam a fazer reconhecer uma identidade social, a exibir uma maneira própria de ser no mundo, a significar simbolicamente um estatuto e uma posição; enfim, as formas institucionalizadas e objetivadas em virtude das quais "representantes" (instâncias coletivas ou individuais singulares) marcam de modo visível e perpétuo a
} 
lógica, pois é mediante a sua interação que se constitui as estruturas de poder.

O poder, na sociedade em rede, é fragmentado, pois o processo de globalização enfraqueceu a hegemonia do Estado como regulador de todas as instâncias, considerando que muitas delas estão além do âmbito nacional, nos grandes conglomerados transnacionais. Essa característica pós-moderna, que aceita o efêmero, o fragmentário e o descontínuo, deslocando o Estado como estrutura central do poder, associando-o ao conhecimento e à informação, pode ser encontrada na obra de Jean-François Lyotard, "A Condição Pós-Moderna", publicada no final da década de 1970. As inovações tecnológicas, a queda do comunismo e readequação do capitalismo são fatores apontados por Castells como formadores dessa sociedade pós-industrial, a estrutura social em redes.

Una red es um conjunto de nodos interconectados. Los nodos pueden tener mayor o menor relevancia para el conjunto de la rede, (...) y su función y significado dependen de los programas de la red y de su interacción com otros nodos de ésta. (...) Los nodos existen y funcionan exclusivamente como componentes de las redes. La red es la unidad, no el nodo. En la vida social las redes son estructuras (CASTELLS,2009,p. 45, grifo nosso).

Dessa forma, podemos destacar que a sociedade em rede é, por excelência, globalizada, tendo como base 'nós conectores' que realizam os fluxos de mensagens. Tal processo transcende as barreiras de tempo e espaço, através da tecnologia, especialmente a tecnologia da comunicação que permite a conexão entre os diferentes pontos que constituem a sociedade em rede. Entretanto, não são todos que participam desse processo globalizado, mas são todos afetados por ele.

La sociedad en red funciona sobre la base de una lógica binaria de inclusiónexclusión, cuyas fronteras varían en el tiempo, tanto con los cambios de los programas de la red como con las condiciones de funcionamiento de esos programas. También depende de la capacidad de los actores sociales, en los diferentes contextos, para actuar estos programas, modificándolos según sus intereses (CASTELLS, 2009, pp. 52 e 53).

É nesse sentido que podemos observar a capacidade relacional do poder, destacada por Castells, na qual a resistência gera um contrapoder, que desperta redes de segurança, gerando novas redes de poder. Inicialmente, pode parecer um pouco confuso e hermético, mas o que ocorre é uma relação simbiótica, onde as alterações das conexões das 
redes, por ações de resistência, acabam por reconfigurá-las, buscando novas alternativas de segurança. Assim como as formas e as relações de poder se redefiniram ao longo dos anos, dominação e resistência trocam de característica segundo a estrutura social.

Ao considerar a acuidade da comunicação na sociedade em rede e a constituição e o exercício de poder nesse processo, proponho pensar essa estrutura e suas imbricações a partir do museu, percebendo-o como um espaço de comunicação. Nesse sentido, pretendo analisar como se estabelecem às relações entre Museu - Poder - Memória, e como isso está se estruturando na sociedade brasileira na última década, incluindo a constituição de trabalhos de memória organizacional e constituição de espaços museais em empresas públicas e privadas. Para tanto, inicialmente serão descritos alguns conceitos e tipologias de museus, sua relação com a memória e com o poder e suas transformações que suscitaram a criação de políticas públicas para área museológica no Brasil. Em seguimento, pretendo realizar algumas considerações de como as empresas se inserem nesse contexto, buscando estabelecer determinados enquadramentos através de suas histórias.

\section{A (re)significação do Museu}

\footnotetext{
Os museus são casas que guardam e apresentam sonhos, sentimentos, pensamentos e intuições que ganham corpo através de imagens, cores, sons e formas. Os museus são pontes, portas e janelas que ligam e desligam mundos, tempos, culturas e pessoas diferentes. Os museus são conceitos e práticas em metamorfose (IBRAM/ ibram.org.br).
}

Da mesma forma que a sociedade não é homogênea, os museus também não são blocos unívocos. Eles são espaços de disputas, seletivos e conflitantes, trabalhando diretamente numa relação dialética entre memória e esquecimento. "Suponho que se engana quem pensa que há humanidade possível fora da tensão entre o esquecimento e a memória" (CHAGAS, 2005,p.24). Tal tensão faz parte do cotidiano das instituições museológicas. Nesse sentido, nos afastamos da ideia de museu, preponderante no século XIX, quando era idealizado como "arcabouço do passado e guardião da verdade", onde estava exposta a "história oficial".

O museu contemporâneo seleciona os 'vestígios' do passado, organizando discursos para promover e veicular suas representações sobre o pretérito, o presente e o que deverá permanecer para o devir. "Sua ação básica desenrola-se em torno da seleção e 
conservação de um dado conjunto de documentos, objetos, artefatos ou imagens, e na comunicação dos conteúdos que deseja apresentar" (POSSAMAI, 2001, p.10). Ele é produtor e divulgador de sentidos na sociedade, se constituindo como uma instituição política, que pode se tornar veículo de cidadania. O museu não é uma estrutura estática, é um processo dinâmico, um espaço discursivo e interpretativo em permanente relação com os atores sociais. Para melhor compreendermos a construção dos discursos museológicos, podemos utilizar a analogia apresentada no filme "Narradores de Javé2", pelo personagem Antônio Biá (protagonizado por José Dumont) quando começa a escrever a "história grande de Javé", a partir dos relatos de seus moradores. Em uma das sequências desta produção cinematográfica, Biá relaciona a memória ao lápis e a borracha ao esquecimento, justificando que desta forma as memórias estão em permanente (re)construção. Assim, vão sendo constituídas as histórias que são expostas no museu para provocar, seduzir, socializar, trocar informações e comunicar.

Nesse sentido, observa-se uma re-significação nos museus, na qual as premissas de conservação e preservação cedem espaço para a comunicação, onde o objeto museal, além de tombado e salvaguardado, deve ser explorado, relacionado e interpretado. Esse processo acompanha as transformações que provocaram a configuração da sociedade em rede. "Os museus como conectores culturais de espaço e tempo" (CATELLS, 2008) potencializam as diferentes alternativas de conexões temporais e espaciais, fato que elucida a criação dos variados tipos de museus: virtuais, itinerantes, comunitários, ecomuseus ${ }^{3}$, entre outros. Tal multiplicidade demonstra a potencialidade desses espaços como instrumentos para a harmonia social, através da sua capacidade de realizar diferentes conexões, trabalhando a pluralidade expressada na sociedade contemporânea.

As diferentes tipologias de museus são exemplo de como essas instituições podem corroborar com a lógica dominante, mas também como processos de resistência, buscando vias alternativas para combatê-la, (re)constituindo elos de identificação. Ao analisarmos o papel dos museus na atualidade, percebemos a intrínseca relação com o poder, embora ela esteja presente desde os remotos tempos, quando o conceito museu surgiu na Grécia Antiga.

O vocábulo museu, como se sabe, tem origem na Grécia, no Templo das Musas (Museión). As musas, por seu turno, foram geradas a partir da união mítica

\footnotetext{
2 Dirigido por Eliane Caffé, produzido por Bananeira Filmes, 2003.

3 Essa tipologia é baseada na musealização de um território no tempo social, a partir do qual a valorização é dada aos processos naturais e culturais, e não aos objetos.
} 
celebrada entre Zeus (identificado com o poder) e Mnemósine (identificada com a memória). O retorno à origem do termo museu não tem nada de novo. Diversos textos trazem essa referência. Avançando um pouco pode-se reconhecer, ao lado de Pierre Nora (1984), que os museus vinculados às musas por herança materna (matrimônio) são "lugares de memória"; mas por herança paterna (patrimônio) são configurações e dispositivos de poder. Assim, os museus são a um só tempo: herdeiros de memória e de poder. Estes dois conceitos estão permanentemente articulados nas instituições museológicas (CHAGAS, s/d, p. 2).

A partir do que apresenta o museólogo Mario Chagas, podemos perceber a importância da memória e do poder como características estruturantes das instituições museológicas. Através da prática relacional entre memória/esquecimento e poder é que se origina a criação, a consagração e a circulação dos discursos e bens culturais que encontramos nos museus. Assim como afirma Pierre Bourdieu, em seu livro "A produção da crença" (2001), a legitimação dos bens simbólicos se encontra na energia acumulada na história de cada campo, constituída por meio de lutas e conflitos pela disputa de autoridades.

\title{
Políticas públicas nos museus brasileiros
}

\begin{abstract}
Há um momento e um território em que o canto da memória se encontra com outras memórias e outros cantos. E se transforma a partir dos encontros feitos. Os museus de pedra e cal e os museus virtuais são baús abertos da memória afetiva da sociedade, da subjetividade coletiva do país, da soma dos museus pessoais (Gilberto Gil, 2004).
\end{abstract}

Por meio de uma relação dialógica com a comunidade, os museus contemporâneos são espaços multidisciplinares que trabalham com preservação, conservação, comunicação, educação, investigação, entre outras ações nas diferentes áreas do conhecimento. No entanto, para promover o desenvolvimento desses espaços museais é imprescindível a elaboração de políticas públicas. "As políticas públicas dão substrato democrático para a viabilização de políticas de Estado que, transcendendo governos, possam viabilizar políticas nacionais mais permanentes" (RUBIM, 2010, p. 36), principalmente se considerarmos a tradição assinalada no artigo "Políticas culturais no Brasil: itinerários e atualidades", de Antonio Albino Canelas Rubim (2010), sobre o percurso das políticas culturais no Brasil, marcada pela ausência, pelo autoritarismo e pela instabilidade. Nessa pesquisa, Rubim buscou, a partir de uma bibliografia dispersa, analisar e avaliar os diferentes momentos da cultura no Brasil, finalizando com as políticas culturais desenvolvidas pelo 
governo Lula, nas gestões dos ministros Gilberto Gil e Juca Ferreira.

O museu como um lugar social para negociar e pautar ações estratégicas, como um espaço do cotidiano, interativo e dialógico começou a ‘tomar corpo’ na década de 1970, através dos indícios da Nova Museologia ${ }^{4}$, que se consolidou em 1984, com a criação do Movimento Internacional da Nova Museologia (MINOM). Nos últimos anos, as transformações ocorridas conduziram a mudanças no Ministério da Cultura, referentes à área de museus.

No Brasil, no período de 2003 a 2009, pode ser observada uma trajetória que possui continuidade e um aprofundamento de um projeto de mudanças institucionais. Esse projeto exige e cria condições para novas relações entre museu, Estado e sociedade. (...) do ponto de vista do Estado e das ações que regem as políticas museológicas, esta continuidade e coerência de ações estão assinaladas na existência de marcos estruturantes, a partir da constituição da Política Nacional de Museus (PNM): a criação do Departamento de Museus e Centros Culturais (DEMU); a formulação e institucionalização do Sistema Brasileiro de Museus (SBM); o estabelecimento do Estatuto dos Museus (EM); e, finalmente; a aprovação e constituição do Instituto Brasileiro de Museus (IBRAM) (MORAES, 2009, p.60).

Faz-se importante destacar que todas as ações e reformulações na área museológica geram uma nova demanda de mercado, buscando desenvolver cursos de formação e especialização para profissionais de museu ${ }^{5}$. Nesse sentido, a constituição do IBRAM, em 2009 - uma autarquia federal vinculada ao Ministério da Cultura - através da Lei $\mathrm{n}^{\circ} 11.906$, vem respaldar e regulamentar todo esse processo. Os objetivos do Instituto estão estruturados para fomentar a criação de novas instituições, assim como para o desenvolvimento das já existentes, procurando melhores formas de expansão e manutenção do acervo, aumento de freqüência, arrecadação financeira, descentralização, entre outros aspectos relacionados à gestão. Dessa forma, podemos constatar que, a partir do início do segundo milênio, a re-significação dos museus brasileiros esta sendo acompanhada pela constituição de políticas públicas.

\section{Relações dialéticas: Poder, Memória e Esquecimento}

4 Soma-se a constituição desse movimento, outros fatores antecessores e predecessores, tais como a criação do Conselho Internacional de Museu (ICOM), em 1946; a Declaração de Quebec, em 1984; a regulamentação da profissão de museólogo no Brasil, em 1984; etc.

5 Nesse caso podemos destacar os cursos de Museologia (disciplina que trata de estudar a relação entre o homem 
A partir da percepção da memória como um instrumento de poder e de constituição de identidade podemos compreender melhor como temáticas, antes destinadas a debates acadêmicos e elucubrações filosóficas passaram a ocupar espaços em instituições empresariais. Entretanto, assim como o poder está imbricado ao conceito de museu desde sua origem, a memória é organizada sob o sentido legitimador como prática secular. A institucionalização de ritos simbólicos - atos comemorativos - marcou as transformações da Europa no século XIX, “(...) os poderes fomentaram várias liturgias de recordação, tendo em vista socializar e enraizar a(s) nova(s) memória(s) em construção (ou em processo de refundação)" (CATROGA, 2001, p. 57). Segundo Castells, o poder está na capacidade de modelar a mente ${ }^{6}$ através de processos de comunicação, relacionando o conteúdo e o formato da mensagem com as redes neurais de associação que surgem da interação com a organização social. Ao ativar as redes adequadas é que se estimulará o processo de comunicação, quando forem estabelecidas imagens mentais da percepção com imagens da memória.

Los sentimentos procesan emociones en la mente en el contexto de la memoria (es decir, los sentimentos incluyen asociaciones com otros acontecimientos, ya sean experimentados directamente por la persona o transmitidos genética $o$ culturalmente) (Castells, 2009, p. 195).

Nesse sentido, podemos perceber a prática comemorativa como uma forma de enquadramento da mente humana. É através da seleção de determinados elementos que se constituiu o discurso museológico, objetivando estimular sentimentos que permanecem na memória, direta ou indiretamente registrados. Tanto as memórias individuais, quanto coletivas, são construção que estão sujeitas a transformações e flutuações. Conforme Michael Pollack (1992), a memória é constituída por três elementos: os acontecimentos vividos pessoalmente; os acontecimentos 'hereditários', quando se refere a fatos presenciados pelo grupo à qual a pessoa se sente pertencer, ou seja, que não são vivenciados pessoalmente, mas apropriados por meio do imaginário; e a memória constituída por pessoas e personagens, podendo-se ainda considerar os lugares de memória, aqueles associados a alguma lembrança. Nesse sentido, podemos associar esse processo social com a análise política de enquadramento da mente proposta por Castells, onde o despertar de sentimentos propicia os

\footnotetext{
e o bem cultural num determinado espaço/cenário).

${ }^{6}$ Conforme Castells, a mente é um processo, não um órgão. Um processo material que se produz no cérebro ao interagir com o corpo. (Castells, 2009)
} 
processos associativos que estabelecem as relações.

A priori, a memória é pensada como algo distante do prosaico, fidedigna aos fatos passados, o arcabouço da verdade, algo pronto, à disposição. No entanto, essas características são ilusórias. A representação de memória pode ser elucidada a partir do que coloca Pierre Nora sobre esse conceito:

\begin{abstract}
A memória é vivida sempre por grupos vivos e, nesse sentido, ela está em permanente evolução aberta à dialética da lembrança e do esquecimento inconsciente de suas deformações sucessivas, vulnerável a todos os usos e manipulações, susceptível de longas latências e de repentinas revitalizações. (...) A memória é um fenômeno sempre atual, um elo vivido no eterno presente; (...). Porque é afetiva e mágica, a memória não se acomoda a detalhes que a confortam; ela se alimenta de lembranças vagas, telescópicas, globais ou flutuantes, particulares ou simbólicas, sensível a todas as transferências, cenas, censura ou projeções. (...) é, por natureza, múltipla e desacelerada, coletiva, plural e individualizada. (NORA, 1993, p. 9).
\end{abstract}

A memória ${ }^{7}$ parece ser um fenômeno individualizado, no entanto, ela deve ser compreendida, sobretudo, como uma construção coletiva e social, marcada por desencontros, pela disparidade temporal e espacial, por disputas de gênero, étnicas, de habitus $^{8}$, entre outros fatores que interferem na organização das memórias individuais e coletivas.

Borges, em seu conto "Funes, O Memorioso", nos apresenta um homem incapaz de esquecer. Funes, um simples peão de uma estância no Uruguai, adquire a incrível capacidade de decorar e recitar obras clássicas inteiras, em latim, lendo-as apenas uma vez. Recordar-se-ia detalhadamente segundo a segundo vivido em um dia, o balançar de cada uma das folhas de uma árvore ao vento, os mais insignificantes movimentos de um cão passando em frente a sua janela. Carregaria essas lembranças para o resto de sua vida. Elas jamais deixariam, em nenhum instante, sua memória. O acúmulo de informações se torna algo insuportável. Embora adquirisse a capacidade do "não esquecimento," isso não significava

\footnotetext{
7 Em seus estudos, Maurice Halbwachs (1990) busca compreender os quadros sociais que compõem a memória. Para ele a memória aparentemente mais particular remete a um grupo. O indivíduo carrega em si a lembrança, mas está sempre interagindo com a sociedade, seus grupos e instituições.

${ }^{8}$ Neste caso, se compreende o conceito de "habitus" a partir da definição de Pierre Bourdieu, em que [os habitus] "são sistemas de disposições duráveis e transponíveis, estruturas estruturadas predispostas a funcionar como estruturas estruturantes, isto é, a funcionar como princípios geradores e organizadores de práticas e de representações que podem ser objetivamente adaptadas a seu objetivo sem supor que se tenham em mira conscientemente estes fins e o controle das operações necessárias para obtê-los (...)”. (BOURDIEU apud CUCHE, 2002, P. 117)
} 
um aumento em sua inteligência. Repetia suas complexas e longas leituras como se fosse um gravador, era incapaz de interpretar, 'digerir', reprocessar a gigantesca quantidade de informação registrada. Por fim, não existia mais o que conhecemos como memória, que por definição é maleável, seletiva, contraditória e afetiva. O Memorioso estava condenado a viver um eterno presente, incapaz de mudar as imagens indelevelmente marcadas em sua mente.

Dessa forma, podemos verificar que não existe memória sem esquecimento, que a relação dialética entre o esquecer e o lembrar é o que constituí a memória. Conforme considerou Friedrich Nietzsche, no século XIX:

\begin{abstract}
Imaginemos, para tomar um exemplo extremo, um homem que estivesse condenado a ver em tudo um devir (Werden): um homem assim não acreditaria mais na sua própria existência, não acreditaria mais em si, veria tudo se dissolver numa multidão de pontos móveis e deixar-se-ia arrastar por esta torrente do devir: como um verdadeiro discípulo de Heráclito, ele acabaria por nem sequer ousar mexer um dedo. Toda a ação exige esquecimento, assim como toda a vida orgânica exige não somente a luz, mas também a escuridão (NIETZSCHE, 2005, p. 72, grifo nosso)
\end{abstract}

A seleção que organiza as memórias individuais e coletivas faz parte do processo de constituição da identidade, que também se configura como uma estrutura discursiva, seletiva e fragmentária em constante construção. Segundo HALL (2000), o processo de identificação nunca é definitivamente determinado, a constituição da identidade é um processo de articulação e adaptação constante. Neste contínuo constituir da identificação, torna-se indispensável o 'outro', a identidade opera pela alteridade, que necessita gerar um discurso de delimitação de fronteiras simbólicas, que separam o 'eu' do 'outro'. O fato da identidade estar em constante construção, atendendo as diferentes contingências e necessidades da sociedade através do tempo, não impede que se formem "pontos de apego temporário", dessa maneira, as identidades seriam as posições que os sujeitos são conduzidos a assumir dentro do discurso construído pela sociedade na qual se insere. Nestes pontos de apego, podemos perceber aqueles que estão dentro da fronteira, o que poderíamos considerar como semelhantes, que compartilham características culturais, religiosas, partidárias, étnicas, econômicas, entre outras. Entretanto, o ponto de referência e manutenção da identidade está no além da fronteira, ou seja, se constitui e/ou reconstitui a partir do alheio, do diferente.

Podemos, portanto, dizer que a memória é um elemento constituinte do sentimento de identidade, tanto individual como coletiva, na medida em que ela é também um

INTRATEXTOS, Rio de Janeiro, 3(1): 1-15,2011 
fator extremamente importante do sentimento de continuidade e de coerência de uma pessoa ou de um grupo em sua reconstrução de si (POLLAK, 1992 p. 203).

$\mathrm{Na}$ medida em que a memória é o reconhecimento do passado, através da recordação, a história é representação desse mesmo passado constituído através de vestígios, indícios (documentos e monumentos) que são compilados e investigados com objetivo de alcançar a verossimilhança. Segundo Paul Ricouer (2007), para compreender o passado se busca uma dada representação do pretérito a fim de representar um passado possível. Nesse sentido, a representação se constitui como objeto e ferramenta da(s) história(s), a partir de diferentes interpretações. Considerar as múltiplas possibilidades de percepções não legitima a abertura irrestrita ao ato imaginativo, pois, como refletiu Umberco Eco, em sua obra "Os limites da interpretação" (1990), dizer que um texto não tem fim não significa que todo ato de interpretação é válido. Entretanto as construções e interpretações podem ser conduzidas à um enquadramento que possibilite a constituição de estruturas de poder e de resistência 'contrapoder'. Assim como em exemplos de desconstrução fornecidos por Derrida, no qual a "desconstrução não significa passar de um conceito para outro e sim derrubar e aplanar uma ordem conceitual ou a não-ordem conceitual com que o texto está articulado" (DERRIDA, 1972 apud ECO, 1990, p. 19).

\section{Considerações Finais}

Podemos observar que, nos últimos anos, há um pungente crescimento de projetos de memória em pequenas, médias e grandes empresas. Uma tendência que vem crescendo no Brasil desde a década de 1990. Essas propostas são organizadas de diferentes maneiras, como formação de Centros de Documentação e Memória, publicações de livros, organização de exposições, trabalhos de história oral ${ }^{9}$, entre outros. A Responsabilidade Histórica passa a fazer parte da Social, na medida em que há a compreensão dos gestores de seu papel histórico dentro de seu segmento e de sua comunidade, nesse sentido, essa prerrogativa se torna cada

\footnotetext{
${ }^{9}$ Segundo Paul Thompson, em entrevista concedida no Brasil, quando realizou uma palestra no II Encontro Internacional de Museus Empresariais, organizado pela Associação Brasileira de Comunicação Empresarial em 2002, a história oral pode trazer, em termos de resultados às empresas, o envolvimento dos consumidores com a marca. "No momento em que ela está no imaginário das pessoas - como, por exemplo, uma marca de sabão em pó muito tradicional - você pode ver como as pessoas lavavam roupas antes e como estão lavando agora, como
} INTRATEXTOS, Rio de Janeiro, 3(1): 1-15,2011 
vez mais presente nas missões das instituições. Tais iniciativas alteram, de diversas formas, a relação da empresa com seus públicos - externos e internos - proporcionando um novo diálogo com a sociedade. Dessa forma, podemos identificar uma nova preocupação entre os gestores, pois comunicar as histórias e memórias de uma empresa passa a ser também uma questão estratégica. Nesse sentido, Beatriz Sarlo ( apud FIGUEIREDO, 2009, p. 16) salienta que "as operações com a história entraram no mercado simbólico do capitalismo tardio com tanta eficiência como quando foram objeto privilegiado das instituições escolares desde o fim do século XIX”.

A partir dessas iniciativas, observamos um novo fenômeno no campo museal: a presença de empresas neste cenário. Considerando que essa atividade foi historicamente desenvolvida pelo Estado ou por setores culturais, as empresas começam a ocupar um papel significativo na constituição de museus, na medida em que percebem esses espaços como uma nova forma de comunicação e núcleos de poder estabelecidos em redes.

Em breve retrospectiva sobre o conceito de memória empresarial, segundo Beth Totini e Elida Gagete (2004), verificamos que ele adquiriu novos sentidos em meados da década de 1920, após a criação, nos Estados Unidos, da Business Historical Society e da criação, em Harvard, da disciplina História Empresarial. Esse objeto de estudo acadêmico buscava apreender as técnicas administrativas de grandes empresários sobre seus negócios. Sob a influência dos Estados Unidos, esse novo conceito começou a ser desenvolvido em países da Europa, como, por exemplo, França e Inglaterra. Ao longo do século XX, esse estudo focalizado na análise econômica passou a abranger outros aspectos, ou seja, temas transversais à trajetória da empresa passaram a compor uma nova perspectiva. $\mathrm{O}$ surgimento da Nova História ${ }^{10}$ teve forte influência nesse processo, pois trouxe a dimensão do simbólico para a memória empresarial. Dessa forma, a história de uma empresa passou a adquirir importância a partir de um discurso construído no contexto social, destacando essas instituições como agentes históricos, ou seja, também como construtores das estruturas que as envolvem.

ele fez parte da vida daquela sociedade".

${ }^{10}$ A Nova História expandiu o campo de ação do conhecimento histórico, permitindo a utilização de novos temas e fontes de pesquisa, transformando os paradigmas da produção de conhecimento nesta área. Com a aceitação cada vez maior da subjetividade, sensibilidades e representações, a música, a pintura, o cinema, a arquitetura, a memória e a oralidade passaram a fazer parte do arsenal do historiador. Veja BURKE (2005) e

INTRATEXTOS, Rio de Janeiro, 3(1): 1-15,2011 
No Brasil, podemos apontar para profundas mudanças a partir dos anos 1980, com o processo de redemocratização do país. O retorno à democracia apontava novos direcionamentos estruturais, exigindo novas prerrogativas às empresas. Tanto as relações internas, quanto externas, cambiavam para outra concepção dialógica, com a premência de atender às novas exigências do mercado. Assim, a década de 1990 foi marcada por uma reestruturação organizacional, ordenada para a busca de certificações de qualidade, maior transparência nas atividades institucionais e articulações na busca de um maior engajamento social.

\begin{abstract}
Diante do enfraquecimento das formas tradicionais de relações públicas e de comunicação com o objetivo de envolver os empregados e outros públicos, a história organizacional começou a se firmar como uma nova perspectiva para o reforço, principalmente, do sentimento de pertença dos empregados, como protagonistas fundamentais das realizações, dos bens, dos serviços e da própria sustentação dos empreendimentos.(...) deixando os trabalhadores de ser receptores passivos para se tornarem atores envolvidos e participantes (NASSAR, 2006, p. 22).
\end{abstract}

Em evidência, o trabalhador passa a ser sujeito dessas trajetórias, se identificando com a empresa a partir de uma história compartilhada. É esse sentimento de pertencimento que fortifica as relações internas das instituições e corrobora com a constituição da sua identidade, fator que valoriza sua marca e proporciona um lugar de destaque no mercado competitivo. Portanto, quando a empresa passa a trabalhar com essa perspectiva histórica, considerando seu papel na sociedade e seu envolvimento com a comunidade, a memória empresarial passa a compor um elemento fundamental na comunicação dessas instituições, que promove identidade e credibilidade entre os atores sociais internos e externos.

Segundo Karen Worcman (2004), a Memória Empresarial não somente evoca o passado da empresa, mas, sobretudo, o uso que ela faz de sua história. Nesse sentido, podemos pensá-la como marco referencial para enquadrar, entre seus diferentes públicos, a imagem da instituição que se pretende constituir e comunicar através de efemérides e processos memorialistas. Esta ação pretende despertar sentimentos e emoções que conduzam a efeitos cognitivos que reforcem suas relações e estruturas de poder. 


\section{Referências Bibliográfica}

BURKE, Peter. O Que é História Cultural? 2. ed. Rio de Janeiro: Zahar, 2005.

BORGES, Jorge Luís. Ficções. São Paulo: Globo, 1999.

BOURDIEU, Pierre. A Produção da Crença. Contribuição para uma economia dos bens simbólicos. 3 ed. Porto Alegre: Zouk, 2001.

RUBIM, Antônio. Políticas Culturais no Brasil: Itinerários e Atualidade. In. BOLAÑO, César; GOLIN, Cida; BRITTOS, Valério. Economia da Arte e da Cultura. São Paulo: Itaú Cultural, 2010.

CASTELLS, Manuel. A Sociedade em Rede. São Paulo: Paz e Terra, 2008.

Comunicación y Poder. Madrid: Alianza, 2009.

CATROGA, Fernando. Memória, História e Historiografia. Coimbra: Quarteto, 2001.

CHAGAS, Mario. Museus: antropofagia da memória e do patrimônio. In: CHAGAS, Mario (Org.) Revista do Patrimônio Histórico e Artístico Nacional, Brasília, n. 31, Ministério da Cultura, Instituto do Patrimônico Histórico e Artístico Nacional, 2005.

CHAGAS, Mario. Memória e Poder: contribuição para a teoria e a prática nos ecomuseus. Disponível em: <http://www.quarteirao.com.br/pdf/mchagas.pdf $>$. Acesso em: 20 jun. 2011.

CHARTIER, Roger. O Mundo como Representação. Estudos Avançados, São Paulo, v. 5, n.11, 1991, jan. Disponível em <http://www.scielo.br/scielo.php?pid=S010340141991000100010\&script=sci_arttext\&tlng=em>. Acesso em: 13 mar. 2009.

CUCHE, Denys. A Noção de Cultura nas Ciências. Bauru: EDUSC, 2002.

THOMPSON, Paul. Recordar é Viver. In. DAMANTE, Nara. Entrevista disponível em $<<$ http://www.aberje.com.br/revista/antigas/rev_36_entrevista.htm $\gg$ Acessado em 05/08/2010.

ECO, Umberto. Os limites da interpretação. São Paulo: Perspectiva, 1990.

FIGUEIREDO, Mirian Colares. Da Memória dos Trabalhadores a Memória da Petrobrás: A História de um Projeto. 2009. Dissertação (Mestrado em História) -

Programa de Pós-Graduação em História, Política e Bens Culturais, Fundação Getúlio Vargas (CPDOC). Rio de Janeiro, 2009.

GIL, Gilberto. A importância dos baús abertos da nossa memória afetiva. Disponível em:

INTRATEXTOS, Rio de Janeiro, 3(1): 1-15,2011 
<http://www.wooz.org.br/culturagilmuseu.htm>. Acesso em: 10 jul. 2010.

HALBWACHS, Maurice. A Memória Coletiva. São Paulo: Vértice, 1990.

HALL, Stuart. Quem Precisa da Identidade? In. DA SILVA, Tomás Tadeu. Identidade e Diferença: A Perspectiva dos Estudos Culturais. Petrópolis: Vozes, 2000.

LYOTARD, Jean-François. A Condição Pós-Moderna. Rio de Janeiro: José Olympio, 1998.

NASSAR, Paulo. Relações Públicas e História Empresarial no Brasil. 2006. Tese (Doutoramento em Ciências da Comunicação). Programa de Pós-Graduação da Escola de Comunicação e Artes da Universidade de São, Paulo, São Paulo, 2006.

NIETZSCHE, Friedrich. II Consideração Intempestiva sobre a utilidade e os inconvenientes da História para a vida (1874). In. SOBRINHO, Noelí. Escritos sobre História. São Paulo: Editora PUCRio; Edições Loyola, 2005.

NORA, Pierre. Entre Memória e História: a problemática dos lugares. Revista Projeto História, São Paulo, n. 10, p. 07-28. 1993

PESAVENTO, Sandra Jatahy. História e História Cultural. 2. ed. Belo Horizonte: Autêntica, 2005.

POLLAK, Michael. Memória e Identidade Social. Estudos Históricos, v. 5, n. 10, p. 200$212,1992$.

POSSAMAI, Zita. Nos Bastidores do Museu. Patrimônio e Passado da Cidade de Porto Alegre. Porto Alegre: EST Edições, 2001.

TOTINI, Beth; GAGETE, Élida. Memória Empresarial: Uma Análise de sua Evolução. In: Memória de Empresa. São Paulo: Aberje Editorial, 2004, pp. 113-126.

WORCMAN, Karen. Memória do Futuro: Um Desafio. In: Memória de Empresa. São Paulo: Aberje Editorial, 2004, pp. 23-30

BRASIL. Instituto Brasileiro de Mineração. Disponível em: 〈http://www.ibram.org.br/>. Acesso em: 10/07/2011. 